\title{
Saúde mental e defesa da vida em tempos de pandemia
}

Mental health and the defense of life in times of pandemic

Francisca Maria Carvalho Cardoso* Edna Maria Goulart Joazeiro**

\begin{abstract}
Resumo - O artigo analisa os desafios e potencialidades na saúde mental na perspectiva analítica dos protagonistas da produção do cuidado no trabalho à pessoa com transtorno mental, nos equipamentos da Rede de Atenção Psicossocial nos municípios de Jaicós e Paulistana na Chapada Vale do Itaim (PI), durante a pandemia. Trata-se de pesquisa qualitativa com fonte primária de informação mediante o uso de tecnologia remota, nas entrevistas e grupos focais com profissionais dos municípios supramencionados. Teve como fonte secundária bases de dados públicos e literatura especializada da temática. A análise revela que os agravos à saúde decorrentes da Covid-19 ampliaram a desigualdade social, fragilizaram o SUS e a saúde mental. Revelam a necessidade do fortalecimento da intersetorialidade, da atenção à crise no território e a importância do matriciamento enquanto estratégia para o fortalecimento da $\mathrm{RAS}$ na $\mathrm{AB}$ e as relações de proximidade entre as equipes e a própria sociabilidade tecida entre as mesmas. Palavras-Chave: saúde pública; Sistema Único de Saúde; políticas públicas.
\end{abstract}

\begin{abstract}
This article analyzes the challenges and potential in mental health from the analytical perspective of the main producers of care at work for people with mental disorders, in the Psychosocial Care Network in the municipalities of Jaicós and Paulistana in Chapada Vale do Itaim, Piaui, during the pandemic. It is the result of qualitative research with primary sources of information through the use of remote technology, in interviews and focus groups with professionals from the aforementioned municipalities. Its secondary source was public databases and specialized literature on the subject. The analysis
\end{abstract}

\footnotetext{
* Psicóloga e Licenciada em História. Mestre em Políticas Públicas. Doutoranda pelo Programa de Pós-Graduação em Políticas Públicas da Universidade Federal do Piauí (UFPI) na Linha Cultura, Identidade e Processos Sociais. Membro do Grupo de Estudo e Pesquisa Formação, Trabalho, Desigualdade Social e Políticas Públicas, CNPq, Brasil. E-mail: franciscamariacardoso@gmail.com. ORCID: https://orcid.org/0000-0003-2940-9590.

** Assistente Social e Socióloga. Pós-Doutora em Serviço Social pela Pontifícia Universidade Católica de São Paulo (PUC-SP), Doutora e Mestre em Educação pela Universidade Estadual de Campinas (UNICAMP). Docente do Departamento de Serviço Social e do Programa de Pós-Graduação em Políticas Públicas da Universidade Federal do Piauí (UFPI) na Linha Cultura, Identidade e Processos Sociais. Líder do Grupo de Estudo e Pesquisa Formação, Trabalho, Desigualdade Social e Políticas Públicas, CNPq, Brasil. Bolsista de Produtividade em Pesquisa do CNPq, Brasil. E-mail: emgoulart@uol.com.br ORCID: https://orcid.org/0000-0003-1998-4532.
} 
reveals that COVID-19's health problems increased social inequality, weakened Brazil's Unified Health System, and Mental Health Care system. They reveal the need to strengthen intersectoriality, attention to crisis in the territory, the importance of matrix support as a strategy for strengthening the RAS in $A B$, and the close relationships between the teams and the very sociability woven between them.

Keywords: public health; Unified Health System; public policies.

\section{Introdução}

O artigo dá centralidade aos desafios e potencialidades do trabalho coletivo no campo da saúde mental em dois municípios do estado do Piauí. A partir da perspectiva analítica dos profissionais protagonistas da produção do cuidado junto à pessoa com transtorno mental na atenção à saúde mental, nos equipamentos da Rede de Atenção Psicossocial (Raps) e na atenção básica (AB), focaliza os municípios de Jaicós e Paulistana, situados no Território de Desenvolvimento Chapada Vale do Itaim (PI), no contexto da pandemia da Covid-19.

O recorte territorial deu-se mediado pela intenção de compreender como se materializa a relação entre a atenção especializada e a básica em municípios situados em regiões distantes da capital, Teresina (PI). Analisamos as especificidades e potencialidades em que está posta a produção do cuidado no campo da saúde mental nesses municípios, uma vez que a configuração territorial e populacional de região distante da capital do estado - formado, predominantemente, por municípios de pequeno porte - se torna representativa dos desafios aos quais estão submetidos cerca de $88,9 \%$ dos pequenos municípios que compõem o Piauí.

É nessa perspectiva que o estudo se torna relevante, à medida que nos desafia a tentar contribuir com uma análise criteriosa sobre e nessa realidade, com o objetivo de fortalecer a política pública de saúde, o Sistema Único de Saúde, a saúde mental e a atenção à população com transtorno mental, nessa e em outras regiões que compartilham características e desafios semelhantes, ou seja, de configurarem-se como região composta por municípios de pequeno porte. Torna-se, assim, representativa da condição das diversas regiões do estado, prevalentemente formadas por municípios com população de até 20 mil habitantes. Na Política Nacional de Assistência Social (BRASIL, 2004), são denominados municípios de pequeno porte I. Além disso, os municípios supracitados apresentam uma variabilidade da Raps. 


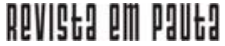

\} SAÚDE MENTAL - CARDOSO, F. M. C.; JOAZEIRO, E. M. G. \}

DOI: $10.12957 /$ REP.2022.63474

Cumpre destacar que o presente artigo é um recorte da pesquisa ${ }^{1}$ de doutorado em andamento no Programa de Pós-Graduação em Políticas Públicas da Universidade Federal do Piauí. Trata-se de pesquisa qualitativa, na qual se busca compreender como o coletivo de profissionais da Rede de Atenção Psicossocial e da atenção básica de Jaicós e Paulistana intervêm nesse campo de conhecimento e de atenção à pessoa com transtorno mental, especialmente em tempos de pandemia da Covid-19.

Utilizamos como fonte primária de informação a entrevista semiestruturada e dois grupos focais com os profissionais da Raps e da atenção básica dos municípios supramencionados. A escolha dos participantes da pesquisa foi feita entre os profissionais que atuam nos Centros de Atenção Psicossocial (Caps) e na atenção básica, constituindo um total de 22 entrevistas, com 13 profissionais de Paulistana e 9 de Jaicós. Após o aceite dos participantes do estudo e da assinatura do Termo de Consentimento Livre e Esclarecido (TCLE), as entrevistas e os dois grupos focais com os/as protagonistas do trabalho foram realizadas entre os meses de novembro de 2020 e fevereiro de 2021, mediante o uso de tecnologia remota, por meio da plataforma Google Meet, em virtude das medidas sanitárias decorrentes da pandemia da Covid-19.

As entrevistas e as narrativas nos dois grupos focais foram gravadas em áudio para permitir criteriosa análise. Posteriormente, esses registros foram transcritos, categorizados, sistematizados e organizados em função dos objetivos do estudo, mediante a triangulação de fontes (MINAYO, 2006). As fontes secundárias de informação utilizadas foram relativas às políticas adstritas ao estudo e aos serviços assistenciais da Rede de Atenção à Saúde (Ras), aos equipamentos da Rede de Atenção Psicossocial (Raps) e da atenção básica $(A B)$, além de incluir bases de dados públicos relativos às dimensões territoriais, demográficas e conceituais do estado do Piauí.

$\mathrm{Na}$ redação do artigo, os depoimentos nas entrevistas e as narrativas nos grupos focais seguem a orientação: identificou-se o número dos profissionais que trabalham na Rede de Atenção Psicossocial, a partir da sequência numérica em que cada profissional foi entrevistado, seguido do registro do município onde trabalham, sendo identificados como município A e B. No que diz respeito às narrativas dos grupos focais, também se optou por identificar os profissionais conforme a sequência numérica de suas intervenções no grupo. Tais escolhas foram feitas para preservar a identidade dos profissionais.

O artigo está dividido em três seções; na primeira se analisa a saúde mental e a atenção à saúde no SUS no contexto da pandemia da Covid-19. Tecemos um breve histórico da saúde e da saúde mental na sua

\footnotetext{
${ }^{1}$ Aprovada pelo Comitê de Ética em Pesquisa CEP-UFPI, CAAE de Cadastramento n. 39432620.0.0000.5214, recebeu parecer favorável em 23 nov. 2020.
} 


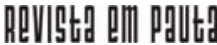

\} SAÚDE MENTAL - CARDOSO, F. M. C.; JOAZEIRO, E. M. G. \}

DOI: $10.12957 /$ REP.2022.63474

relação com o território (SANTOS, 2006), relacionando-o com alguns desafios decorrentes da crise pandêmica. Na segunda seção, SUS, território e municípios de pequeno porte I, assinalamos a relação do SUS com as redes temáticas de atenção em saúde, bem como os desafios da Rede de Atenção Psicossocial em face das características do estado do Piauí. Na última seção, assinalamos o papel do matriciamento e intersetorialidade no território em tempos de pandemia, enfatizando a importância da estratégia do apoio matricial e a perspectiva de análise de profissionais das redes de atenção especializada e básica nos municípios de pequeno porte I. É analisado o lugar que têm ocupado as políticas sociais no trabalho em rede, com foco no contexto da pandemia da Covid-19.

\section{Saúde mental e atenção à saúde no SUS no contexto da pandemia da Covid-19}

Assinala Saraceno (2020, p. 2) que a pandemia da Covid-19 nos possibilitou novas transformações, bem como nos tem convocado a tomar "uma nova consciência sobre a dramática ausência de democracia nos sistemas de Saúde, em geral". O autor ressalta que temos visto durante a pandemia "falta de cultura, organização e infraestrutura capazes de operar inclusive fora dos hospitais". Nessa perspectiva, Mendes e Carnut (2020, p. 23) apontam que a discussão acerca da realidade brasileira, nas análises do financiamento do SUS, "tem sido um processo difícil e tenso no contexto da barbárie do tempo histórico do capitalismo contemporâneo em crise".

Neste percurso, torna-se importante empreender uma aproximação desse processo histórico de constituição do SUS e da saúde mental. Amarante e Nunes (2018, p. 2.068) assinalam que "as políticas de Saúde Mental (SM) e Atenção Psicossocial (AP) no SUS têm relação direta com a ideia-proposta-projeto-movimento-processo da Reforma Sanitária [...], mas guardam algumas singularidades!". A reforma psiquiátrica buscava fortalecer o processo de desinstitucionalização; contudo, é importante pontuar que esse processo "não se limita ao fechamento de hospícios, significa também transformar o conjunto de aparatos científicos, a legislação, a cultura e as relações de poder" (JOAZEIRO; ARAÚJO; ROSA, 2018, p. 72). É somente com a Lei Federal no 10.216/2001 (BRASIL, 2001) que se dá o redirecionamento da assistência em saúde mental.

Assinala Amarante (1996, p. 30) que a desinstitucionalização "é um processo prático de desconstrução e, simultaneamente, um processo de invenção de novas realidades". Assim, na busca pela desinstitucionalização, Vasconcelos (2016, p. 39) assinala que a reforma psiquiátrica no contexto brasileiro desde o seu início no final da década de 1970 constitui-se num "caráter de movimento social integrado às lutas pela redemocratização, contra as violações dos direitos humanos e por políticas 


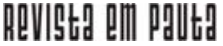

\} SAÚDE MENTAL - CARDOSO, F. M. C.; JOAZEIRO, E. M. G. \}

DOI: $10.12957 /$ REP.2022.63474

sociais universais, mas particularmente tem sido um movimento orgânico à emergência e desenvolvimento do movimento sanitário".

Embora a luta antimanicomial fortaleça a reforma psiquiátrica, em análises recentes Alves et al. (2020, p. 173) que "apesar de engendrar avanços importantes na ampliação de serviços em níveis de atenção primária e secundária - em especial os Caps, é possível dizer que o arcaico ainda persiste através da forte lógica de internações - leitos e AlHs ${ }^{2 \prime}$.

Seixas et al. (2021, p. 11) indagam: "vamos enfrentar essa crise sanitária, ética e política inédita na existência de todos nós usando os mesmos paradigmas e modelos conservadores do campo da Saúde pública e da biomedicina [...]?". A questão é pertinente, uma vez que essa mudança do paradigma hospitalocêntrico para o biopsicossocial é essencial para enfrentarmos a crise vivenciada na saúde e na saúde mental. Essa mudança de paradigma, já arrolada há décadas, se ancora no estabelecimento de uma atenção psicossocial interdisciplinar, isto é, acontece "[...] no território com serviços abertos, universais, de fácil acesso, inspirados na perspectiva de conquista de direitos humanos e da cidadania de seus usuários e familiares, e integrados intersetorialmente" (VASCONCELOS, 2016, p. 37).

Na perspectiva de Pitta, Coutinho e Rocha (2015, p. 761), na organização da assistência à população usuária da saúde mental, mesmo em tempo de crise no país, será necessário, de um lado, "buscar garantir o acesso ao tratamento na sua comunidade de referência, através do cuidado clínico, do uso racional de psicofármacos e de programas de reabilitação psicossocial". Por outro lado, assinalam ainda que "a sua implantação e o desenvolvimento de ações demandam uma radicalização ética capaz de modificar as organizações de serviços e os níveis de complexidade tecnológica do sistema de Saúde" (PITTA; COUTINHO; ROCHA, 2015, p. 761).

\section{SUS, território e municípios de pequeno porte I}

No âmbito do Sistema Único de Saúde no Brasil existem cinco redes temáticas de atenção à saúde (BRASIL, 2010), que são organizadas com base na necessidade de enfrentamento de vulnerabilidades, agravos ou doenças. Essas redes foram estabelecidas após a pactuação tripartite em 2011 e são temáticas por serem pontos prioritários na saúde do país: Rede Cegonha, que tem um recorte de atenção à gestante e à criança até 24 meses; Rede de Atenção Psicossocial (Raps), (BRASIL, 2011a); Rede de Atenção às Pessoas com Doenças Crônicas; Rede de Cuidado à Pessoa com Deficiência; e Rede de Urgência e Emergência (Rue). Todas as redes têm o caráter transversal dos temas: qualificação e educação, informação, regulação e promoção e vigilância à saúde (BRASIL, 2010).

${ }^{2}$ A Sigla refere-se à Autorização de Internação Hospitalar. 


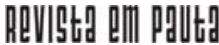

\} SAÚDE MENTAL - CARDOSO, F. M. C.; JOAZEIRO, E. M. G. \}

DOI: $10.12957 /$ REP.2022.63474

Os desafios da Raps não são atuais, mas se tornam mais complexos em tempo de capital pandêmico (ANTUNES, 2020) e de crise sanitária. É nesse contexto que se instaura o capital pandêmico, na "[...] imbricação trágica entre sistema de metabolismo antissocial do capital, crise estrutural e explosão do coronavírus" (ANTUNES, 2020, p. 14).

$\mathrm{Na}$ imbricação trágica assinalada pelo autor, entre o sistema de metabolismo antissocial do capital, a crise estrutural e a pandemia do novo coronavírus, se instaura o capital pandêmico que apresenta o caráter discriminatório em relação às classes sociais, na medida em que é mais letal para aqueles que necessitam de seu trabalho para sobreviver (ANTUNES, 2020).

Assinalam Mendes e Carnut (2020, p. 23) que, ao longo dos últimos 30 anos, que coincidem com a criação do SUS, o Estado brasileiro "não deixou de conceder incentivo à iniciativa privada, impondo riscos à saúde universal". Os autores enfatizam que a EC 95 (BRASIL, 2016) tem "o objetivo de limitar a expansão dos gastos públicos (despesas primárias) pelos próximos 20 anos, mas não o fez para as despesas financeiras, mantendo o alto patamar de pagamento dos juros da dívida por parte do governo" (MENDES; CARNUT, 2020, p. 26-27). Nessa perspectiva "o subfinanciamento do SUS passou a ser transformado num processo de desfinanciamento, configurando um quadro de aniquilamento, a conta-gotas das tentativas de construção de nosso sistema universal" (MENDES; CARNUT, 2020, p. 26).

Paim (2019, p. 21) aponta que o Sistema Único de Saúde tem sua história profundamente marcada pelo subfinanciamento crônico e o desfinanciamento decorrente da Emenda Constitucional no 95, que "comprometem a universalização e a expansão de serviços públicos, tendendo ao agravamento, caso seja concretizada a ameaça do ministro da economia por meio da proposta dos '3 D'- Desindexar, Desobrigar e Desvincular o orçamento". Segundo Seixas et al., (2021, p. 6), "o SUS possui uma grande rede de serviços [...] intensamente sucateada pelos dois últimos governos federais", decorrentes da Emenda Constitucional no 95 EC (95) (BRASIL, 2016), "da nova política nacional de atenção básica e de suas normatizações e "nova" Rede de Atenção Psicossocial" (SEIXAS et al., 2021, p. 6).

Nesta perspectiva analítica, busca-se refletir sobre as múltiplas dimensões e os desafios que estão postos no campo da saúde mental neste território do estado, uma vez que, pela sua configuração territorial e populacional, tem havido uma tendência histórica à centralização dos serviços assistenciais de maior complexidade na capital. Faz sentido, portanto, indagar-se sobre os efeitos da pandemia no processo de atenção à pessoa com transtorno mental, com vistas a compreender como se materializa a relação entre a atenção especializada e a básica em municípios situados em regiões distantes da capital Teresina $(\mathrm{PI})$.

O estado do Piauí se situa na Região Nordeste do Brasil, na zona considerada meio norte do país, em função de ser área intermediária entre 


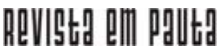

\} SAÚDE MENTAL - CARDOSO, F. M. C.; JOAZEIRO, E. M. G. \}

DOI: $10.12957 /$ REP.2022.63474

o Nordeste e a região Norte-Amazônica, composto por 224 municípios, distribuídos em uma área de 251.529,186 km².

Quadro 1

Municípios do Piauí distribuídos com base no tamanho da população

\begin{tabular}{|c|c|c|c|c|c|c|c|}
\hline $\begin{array}{c}\text { Classes de tamanho } \\
\text { da população }\end{array}$ & \multicolumn{2}{|c|}{$\begin{array}{l}\text { Número de } \\
\text { municipios* }\end{array}$} & \multicolumn{2}{|c|}{ Populaçâo residente* } & \multicolumn{3}{|c|}{ Porte dos municípios } \\
\hline & Quantidade & $\%$ & Total & $\%$ & $\begin{array}{c}\text { Com } \\
\text { base no }\end{array}$ & $N$ & $\%$ \\
\hline Piauí & 224 & & 3.118 .360 & & $\begin{array}{l}\text { PNAS, } \\
(2004)\end{array}$ & & \\
\hline Até 5.000 & 83 & 37,05 & 317.989 & 10,20 & \multirow{3}{*}{$\begin{array}{c}\text { Pequeno } \\
1\end{array}$} & \multirow{3}{*}{199} & \multirow{3}{*}{$\begin{array}{c}88 \\
9 \\
\end{array}$} \\
\hline De 5.001 até 10.000 & 81 & 36,16 & 544.766 & 17,47 & & & \\
\hline De 10.001 até 20.000 & 35 & 15,62 & 477.604 & 15,32 & & & \\
\hline De 20.001 até 50.000 & 20 & 8,93 & 625.128 & 20,05 & $\begin{array}{l}\text { Pequeno } \\
\text { II }\end{array}$ & 20 & 8,9 \\
\hline $\begin{array}{l}\text { De } 50.001 \text { até } \\
100.000\end{array}$ & 03 & 1,34 & 192.938 & 6,19 & Médio & 03 & 1,3 \\
\hline $\begin{array}{l}\text { De } 100.001 \text { até } \\
500.000\end{array}$ & 01 & 0,45 & 145.705 & 4,67 & \multirow[t]{2}{*}{ Grande } & \multirow[t]{2}{*}{02} & \multirow[t]{2}{*}{0,9} \\
\hline Mais de 500.000 & 01 & 0,45 & 814.230 & 26,11 & & & \\
\hline Nordeste & 1.794 & - & 53.081 .950 & - & & & \\
\hline Brasil & 5.565 & - & $\begin{array}{c}190.755 .79 \\
9\end{array}$ & - & & & \\
\hline
\end{tabular}

Fonte: Elaboração própria com base em: Cepro (2012); IBGE (2010);

Piauí (2016).

De acordo com a Política Nacional de Assistência Social (BRASIL, 2004), os municípios brasileiros são apresentados como: pequeno, médio, grande porte e metrópoles. Além disso, são organizados em: 1. pequeno porte I (até 20.000 habitantes); 2. pequeno porte II (de 20.001 a 50.000 habitantes); 3. médio porte (de 50.001 a 100.000 habitantes); 4. grande porte (de 100.001 a 900.000 habitantes); 5. metrópoles (mais de 900.000 habitantes). Conforme já assinalado, a distribuição dos municípios no Piauí tem o predomínio de municípios de pequeno porte I, perfazendo um percentual de $88,9 \%$ dos municípios que compõem essa categoria, conforme o Quadro 1; como exemplos, temos Jaicós e Paulistana, epicentro do nosso estudo.

\section{Matriciamento e intersetorialidade como potencialidade no território em tempos de pandemia}

Nesta seção, analisamos as narrativas dos profissionais com vista a refletir sobre os desafios postos à produção do cuidado em saúde mental no contexto de municípios de pequeno porte I em tempos de pandemia da Covid-19. Tal análise remete ao exercício profissional de um coletivo de 
profissões e ocupações da saúde, a saber: serviço social, psicologia, pedagogia, educação física, enfermagem, medicina e fisioterapia, na interlocução entre profissionais no cuidado à pessoa com transtorno mental e suas famílias no contexto do SUS.

Desse modo, pensar o trabalho em rede é perceber a ação intersetorial como um espaço que convoca o trabalho em rede e que pressupõe a intersetorialidade e as políticas públicas como nova lógica de gestão. Pereira (2014, p. 23) afirma que a intersetorialidade é a "articulação entre setores sociais diversos e especializados". Quanto às condições estratégicas, é entendida como um "instrumento de otimização de setores, competências e relações sinergéticas em prol de um objetivo comum, e prática social compartilhada" (PEREIRA, 2014, p. 23).

A própria concepção de rede remete a diferentes níveis de estabelecimento de relações de compromisso e de tessitura de vínculos. Ora, a atividade de trabalho comporta o acesso às normas antecedentes de natureza diversa, algumas do núcleo de formação de cada profissão; outras, às normas nascidas do campo da saúde, espaço no qual transitam conhecimentos transversais às diversas profissões, quer seja no campo biomédico, da biossegurança, ou os saberes amealhados na dinâmica do processo de atenção compartilhada entre as diversas profissões e ocupações que compõem as equipes especializadas da saúde mental.

Esse trabalho em rede, de promover assembleia, chamando os agentes comunitários de saúde, que é o carro-chefe do PSF [Programa de Saúde da Família] para estar participando, interagindo com a gente, pois a coletividade em rede é muito importante. O matriciamento é um dos pontos mais importantes do Caps, porque se não tiver não vai funcionar. Para funcionar a saúde mental de verdade tem que se trabalhar em rede. (Fragmentos de narrativa do Profissional 2 GF-B).

No depoimento, a profissional assinala a importância do trabalho em rede no espaço da saúde mental; segundo ela, "a coletividade em rede é muito importante", e para tal valoriza o matriciamento enquanto estratégia que busca fortalecer a relação entre a atenção básica e a especializada na saúde mental e deve proporcionar "um suporte técnico-pedagógico" (BRASIL, 2011b, p. 14). O matriciamento se constitui num indicador essencial, que a profissional define como "um dos pontos mais importantes do Caps, porque, se não tiver matriciamento, não vai funcionar. Para funcionar, a Saúde Mental de verdade tem de se trabalhar em rede".

O matriciamento, enquanto concepção e estratégia, visa a efetivar a articulação intersetorial entre os serviços da rede de atenção à saúde, e também requer o fortelecimento entre a política de assistência social e outras políticas públicas. A concepção que ordena as redes se ancora na perspectiva analítica de que temas como qualificação e educação, informação, regulação, promoção e vigilância à saúde precisam ter um caráter transversal no seu interior. 


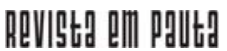

\} SAÚDE MENTAL - CARDOSO, F. M. C.; JOAZEIRO, E. M. G. \}

DOI: $10.12957 /$ REP.2022.63474

No Brasil o matriciamento é uma das tecnologias que buscam a eficácia na atenção em saúde mental. Assinalamos a efetivação dessa prática, que leva as equipes envolvidas no processo a enfrentar os desafios apontados por Iglesias e Avellar (2019, p. 1.248), como, por exemplo: “i) às modificações nas relações de trabalho, ii) a mudança no modo fragmentado de se operar o cuidado em Saúde; iii) mudança na formação em Saúde, centrada na perspectiva biomédica; iv) mudança no modo de praticar saúde que transcenda o setor Saúde". É importante destacar que a intervenção na saúde mental pressupõe que outros serviços da RAS, inclusive de outros níveis de atenção e as demais políticas sociais, sejam sensibilizados para construir sinergia e efetividade.

Numa análise atenta dos depoimentos nas entrevistas e das narrativas dos profissionais nos grupos focais, se apreende a importância da intrassetorialidade tal qual arrolado no fragmento do Profissional 2 GF-B, bem como da intersetorialidade no trabalho e no cuidado em saúde mental, conforme assinalado no depoimento na entrevista do Profissional 1-B. Nele, é valorizada a relação a ser tecida no âmbito da política de saúde no SUS com a política de assistência social, marcadamente para intervir nas interfaces entre vulnerabilidade social, sofrimento psíquico e transtorno mental. Essa intrincada e complexa relação está presente, nos depoimentos, na alusão à multifacética questão da violência autoinfligida, dentre elas, a tentativa e o próprio suicídio.

A intersetorialidade eu acredito que seja efetiva, o trabalho em rede. Então, assim, a gente procura estar se ajudando, por exemplo, a gente desenvolveu recentemente uma capacitação voltada para o combate ao suicídio. Então, a gente procurou trazer profissionais para trabalhar com a gente e debater. Nas lives que a gente realizou, a gente trouxe outros setores, como o Creas, por exemplo. Então, querendo ou não, acaba sendo efetivo. (Fragmentos de depoimento na entrevista do Profissional 1-B).

O Cras, a assistência social, ajudam bastante [...], a gente encontra muitos casos de vulnerabilidade extrema [...] sem instrução. Na repartição pública, quando a gente identifica esses casos, a gente não só encontra o problema de saúde mental, mas outras questões [...], sociais, financeiras, que fogem da nossa governabilidade, e acionamos a assistência social do município, para que eles possam atuar conosco. [...] Então, [...] o trabalho se direciona não só à saúde mental, mas conseguimos dar uma resolutividade na vida da pessoa em outras esferas. (Fragmentos de depoimento na entrevista do Profissional 5-A).

Destacamos, nos depoimentos dos profissionais, o uso reiterado da expressão a gente, que remete à condição de sujeito do trabalho realizado e de partícipe do coletivo que constrói a atenção e a produção do cuidado para a pessoa com transtorno mental e sua família naquela região. O trabalho vivo em ato e o matriciamento fazem parte de uma dimensão 
essencial para fazer emergir uma nova perspectiva de intervenção, uma vez que ambos são fundamentais para a produção da atenção e do cuidado, construindo uma relação sensível da e na rede de saúde, e propiciando o estabelecimento de relações de compromisso com a pessoa com transtorno mental, sua família e a sociedade.

Se considerarmos a proposta do matriciamento em saúde mental, em presença e em tensão com o desafio de contruir uma aproximação entre a atenção básica e atenção especializada em saúde mental, precisamos reconhecer que ambos os níveis de atenção à saúde trabalham com necessidades específicas; respondem, portanto, a níveis de necessidade e se utilizam de diferentes tipos de tecnologia, fato que exige que os protagonistas da atividade do trabalho acedam aos diferentes corpos conceituais epistêmicos, disciplinares e axiológicos.

No fragmento do depoimento da profissional 1-B, ela diz: "nas lives que a gente realizou, a gente trouxe outros setores, como o Creas, por exemplo. Então, querendo ou não, acaba sendo efetivo". A profissional alude ao uso de um instrumento de "encontro virtual", a live, que tem sido amplamente utilizada como uma estratégia de aproximação e de intervenção em tempos de isolamento social decorrente de medidas sanitárias para enfrentamento da pandemia. Nessa alusão, ela faz menção à busca de tessitura de diálogos, tanto no âmbito da saúde quanto das demais políticas sociais públicas, uma vez que essas são imprescindíveis no enfrentamento da questão social na interface entre o campo da saúde e os determinantes sociais em saúde (SARACENO, 2020).

Campos (2020), Minayo e Freire (2020), Seixas et al. (2021) e Werneck e Carvalho (2020) assinalam que a pandemia da Covid-19 evidencia a desigualdade social no Brasil, pois as condições precárias de moradia, trabalho, renda, saneamento básico e acesso a transportes, como também baixos salários e contato com outras pessoas em decorrência da atividade de trabalho, são alguns dos fatores que contribuem para a proliferação do vírus, principalmente em camadas mais pobres. Desse modo, a desigualdade social evidenciada pela pandemia se torna "um terreno fértil para a disseminação da Covid-19, dificultando o isolamento social, restringindo acesso a insumos básicos para higiene e proteção e dificultando a própria assistência aos serviços de Saúde" (MINAYO; FREIRE, 2020, p. 3.556).

A Organização Mundial de Saúde (OMS, 2008) já afirmava, em 2008, a importância da integração de ações de saúde mental na atenção básica, recomendando para os trabalhadores dos serviços de saúde no território o reconhecimento da atenção em saúde mental como parte dos cuidados na atenção básica. Essa, entendida enquanto "ordenadora do cuidado e transversalizadora das práticas de Atenção à Saúde, é confrontada cotidianamente por problemas oriundos do sofrimento mental" (CAMPOS; BEZERRA; JORGE, 2018, p. 2.229). 


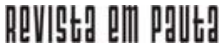

\} SAÚDE MENTAL - CARDOSO, F. M. C.; JOAZEIRO, E. M. G. \}

DOI: $10.12957 /$ REP.2022.63474

Destacamos que, nos municípios de pequeno porte, a crise é atravessada por situações locorregionais; onde há uma articulação local para o atendimento, eventualmente há a necessidade de deslocamento ao hospital psiquiátrico localizado na capital, Teresina, o Hospital Areolino de Abreu.

Os casos de transferência para Teresina são discutidos pelo médico plantonista e pelo psiquiatra que vai fazer a visita. Fazemos a avaliação, algum profissional do Caps, e logo depois o psiquiatra faz a visita quando está em serviço. Quando nós fazemos a avaliação com o serviço, eles decidem se o paciente tem alta para continuar o acompanhamento no município, ou, se não, se for um paciente que necessita ser internado no Areolino [Hospital Areolino de Abreu], ele é encaminhado. São poucos os que precisam ser transferidos, nós damos assistência para que não seja mandado para lá, mas, para que ele possa ser transferido, primeiro falamos com os familiares. (Fragmentos da narrativa do Profissional 1 GF- A - grifos nossos).

Já mandamos vários [usuários] para o Areolino, só que quem faz a regulação é o médico plantonista, e quando a gente faz essa transferência, a gente conversa com o familiar e explica como é. O município dá esse suporte. O hospital dá esse suporte do transporte e a comunicação entre os hospitais. (Fragmentos da narrativa do Profissional 2 GF- B - grifos nossos).

Merhy et al. (2019, p. 73) afirmam que "o trabalho em Saúde está tensionado pelas 'necessidades sociais', interferidas pela estrutura produtiva da sociedade e pelos desejos e demandas de seus usuários diretos". Ora, proteger a vida e recuperar a saúde remetem à importância de estabelecer relações intersetoriais, sendo que essa temática ocupou um importante espaço nas narrativas das equipes de políticas sociais distintas nos grupos focais realizados nos municípios A e B.

Estou ouvindo vocês e eu acho que [a Profissional 1] falou um pouco da nossa equipe. É importante destacar as ações intersetoriais. [...] $A$ gente trabalha muito com a rede, estamos sempre ligados ao Creas, ao Cras, à atenção básica, não é, [declina o nome da Profissional 2]? Então, a nossa relação no município é fácil, temos uma boa relação com todo mundo e sempre que necessário a gente pede socorro mesmo. E é isso. (Fragmentos da narrativa do Profissional 3 GF-A - grifos nossos).

A gente sabe quem é enfermeiro, ou seja, a gente está sempre entrando em contato. [...] a gente já organiza, visita, agenda atendimento, a relação com os serviços é muito boa. (Fragmentos da narrativa do Profissional 1 GF-A - grifos nossos).

Sempre que a gente precisa dessa rede, eles estão ali prontos para esse suporte. Contamos com o apoio do Samu, Cras, Creas, Nasf, dos agentes comunitários de saúde. [...] Ter esse suporte e ter essa equipe toda para nos dar apoio assim que a gente precisar é de fundamental 
importância, tanto para a gente, quanto para o usuário, porque ele se sente acolhido e que pode contar com aquela equipe. (Fragmentos da narrativa do Profissional 1 GF-B - grifos nossos).

Um dos aspectos destacados nos depoimentos e nas narrativas dos grupos diz respeito à configuração de município de pequeno porte I. Foram as relações de proximidade entre as equipes e a própria sociabilidade tecida entre elas que tendem a contribuir para o fortalecimento de ações, mesmo em tempo de pandemia. Contudo, assinalaram que a ausência de dispositivo de Caps modalidade III, somente instalado na capital do estado, fragiliza a estrutura interventiva, à medida que nenhum dos 223 municípios dispõe desse dispositivo com estrutura de atenção à crise em um equipamento comunitário substitutivo ao hospital psiquiátrico, tal qual preconizado pela reforma psiquiátrica no Brasil.

\section{Considerações finais}

O estudo colocou no centro da prática de conhecimento os desafios e as potencialidades no campo da saúde mental em municípios de pequeno porte I do estado do Piauí em tempos de pandemia da Covid-19. Nesse contexto de crise pandêmica e de ampliação da vulnerabilidade social, decorrente das contrarreformas do Estado e de ampliação, constatouse a importância da participação ativa da atenção básica e da atenção especializada no SUS, particularmente no momento pandêmico; todavia, essa articulação entre redes tem sofrido descontinuidades, estando profundamente fragilizada pelos efeitos das contínuas contrarreformas do Estado.

Giovanella et al. (2020) assinalam que a atenção básica é essencial na abordagem comunitária e na vigilância em saúde, em especial, a estratégia saúde da família (ESF), com enfoque comunitário e territorial, pois apresentam resultados significativos na saúde da população. A continuidade do atendimento e o acompanhamento da pessoa com transtorno mental, no seu próprio território, pressupõe uma fina articulação entre a atenção básica e a Raps.

Nessa perspectiva, se a atenção básica deveria ser o centro de comunicação com as redes de saúde, torna-se importante destacar que, em tempos de pandemia, a intervenção do Estado brasileiro, com base nas múltiplas contrarreformas, tem fragilizado o arcabouço do SUS, dificultando o trabalho em saúde e o custeio das políticas sociais públicas. Além disso, cria sérios obstáculos para os protagonistas do trabalho e para a atenção intra e intersetorial em rede, que, em última instância, envolve dimensões políticas, econômicas, culturais e técnicas, e, no limite, coloca seriamente em risco a vida e a cidadania.

Os desafios do trabalho em saúde em situações de ampliada desigualdade social remetem à capacidade de refletir sobre o trabalho, seus 


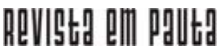

\} SAÚDE MENTAL - CARDOSO, F. M. C.; JOAZEIRO, E. M. G. \}

DOI: $10.12957 /$ REP.2022.63474

desafios, objetivos e limites, fato que pode contribuir para iluminar a travessia a ser efetivada no tempo presente. É sob essa perspectiva de análise que julgamos imprescindível (re)pensar o lugar que a atividade de trabalho ocupa no processo de produção do cuidado e de aproximação entre as equipes da atenção básica, atenção especializada em saúde mental e das demais políticas públicas, visando a reconhecer o valor do trabalho humano no processo de enfrentamento diuturno em face de suas múltiplas invisibilidades e opacidades, para fazer emergir reservas de alternativas a serviço da vida, da cidadania e da superação das desigualdades socioterritoirais.

Cumpre destacar o desafio histórico de buscar construir elos com as demais políticas públicas, visando a reconhecer o valor do trabalho humano construído da e na experiência concreta do trabalho em saúde e em saúde mental no SUS. Esse percurso deve ser feito sob a égide da valorização da importância da produção do cuidado em consonância com o tratar a pessoa com transtorno mental em liberdade, num espaço comunitário e aberto, ancorado no princípio da democracia, da liberdade e da preservação dos direitos de cidadania. Nessa perspectiva, julgamos imprescindível (re)pensar o lugar que o trabalho em saúde ocupa no processo de aproximação entre as equipes da atenção básica e da atenção especializada em saúde mental.

Saraceno (2020, p. 5) reafirma que o futuro da saúde mental se tornará cada vez mais "importante se estiver nas mãos de diversos atores sociais, dos quais enumera os profissionais de saúde mental, organizações comunitárias, ativistas de direitos humanos, juízes, usuários e familiares". Contudo, destaca que "os membros da família terão que conquistar mais poder e equilibrar séculos de opressão e silêncio" (SARACENO, 2020, p. $5)$.

Enfatizamos, ainda, a importância do matriciamento enquanto estratégia que visa a estimular a potencialidade da rede de atenção nos municípios, na perspectiva de contribuir para o fortalecimento do trabalho coletivo em saúde e na saúde mental, além de buscar intensificar a dimensão intersetorial indispensável para o enfrentamento das mútuas e múltiplas relações entre a pessoa com transtorno mental, a questão social e as vulnerabilidades inerentes à experiência de uma vida marcada pela busca da proteção social e de outros e novos sentidos. 


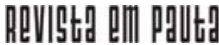

\} SAÚDE MENTAL - CARDOSO, F. M. C.; JOAZEIRO, E. M. G. \}

DOI: $10.12957 /$ REP.2022.63474

\section{Referências}

ALVES, D. F. de A. et al. Reforma psiquiátrica e a dependência brasileira: entre o arcaico e o moderno. Katálysis, Florianópolis, v. 23, n. 1, 2020. Disponível em: https://www.scielo.br/j/rk/a/QtqncyMGyb4JNsBHMv5d GnG/?lang=pt\&format=pdf. Acesso em: 15 jan. 2021.

AMARANTE, P. D. de C. O homem e a serpente: outras histórias para a loucura e a Psiquiatria. Rio de Janeiro: Fiocruz, 1996.

AMARANTE, P. D. de C.; NUNES, M. de O. A reforma psiquiátrica no SUS e a luta por uma sociedade sem manicômios. Ciência e Saúde Coletiva, Rio de Janeiro, v. 23, n. 6, 2018. Disponível em: https://www.mds.gov.br/web arquivos/publicacao/assistencia_social/Normativas/PNAS2004.pdf. Acesso em: 15 jan. 2021.

ANTUNES, R. Coronavírus: o trabalho sob fogo cruzado. São Paulo: Boitempo, 2020.

BRASIL. Ministério da Saúde. Lei n. 10.216, de 6 de abril de 2001. Dispõe sobre a proteção e os direitos das pessoas portadoras de transtornos mentais e redireciona o modelo assistencial em saúde mental. 2001. Disponível em: https://hpm.org.br/wp-content/uploads/2014/09/lei-no-10.216-de-6-deabril-de-2001.pdf. Acesso em: 15 jan. 2021.

BRASIL. Ministério do Desenvolvimento Social e Combate à Fome e a Miséria (MDS). Política Nacional de Assistência Social/Sistema Único de Assistência Social - Pnas -Suas/2004. Norma Operacional Básica-NOB/Suas. Brasília: Secretaria Nacional de Assistência Social, 2004. Disponível em: https:// www.mds.gov.br/webarquivos/publicacao/assistencia_social/Normativas/ PNAS2004.pdf. Acesso em: 15 jun. 2021.

BRASIL. Ministério da Saúde. Portaria n. 4.279, de 30 de dezembro de 2010. Estabelece diretrizes para a organização da rede de atenção à saúde no âmbito do Sistema Único de Saúde (SUS). 2010. Disponível em: http:// bvsms.saude.gov.br/bvs/saudelegis/gm/2010/prt4279_30_12_2010.html. Acesso em: 20 maio 2021.

BRASIL. Ministério da Saúde. Portaria n. 3.088, de 23 de dezembro de 2011a. Institui a Rede de Atenção Psicossocial para pessoas com sofrimento ou transtorno mental e com necessidades decorrentes do uso de crack, álcool e outras drogas, no âmbito do Sistema Único de Saúde (SUS) e dá outras providências. 2011. Disponível em: http://bvsms.saude.gov.br/bvs/ saudelegis/gm/2011/prt3088_23_12_2011_rep.html. Acesso em: 20 fev. 2021. BRASIL. Guia prático de matriciamento em saúde mental. Brasília: Ministério da Saúde, 2011b. Disponível em: http://bvsms.saude.gov.br/bvs/publicacoes/ guia_pratico_matriciamento_saudemental.pdf. Acesso em: 20 jan. 2021. 


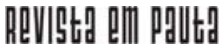

\} SAÚDE MENTAL - CARDOSO, F. M. C.; JOAZEIRO, E. M. G. \}

DOI: $10.12957 /$ REP.2022.63474

BRASIL. Ministério da Saúde. Emenda constitucional n. 95, de 15 de dezembro de 2016. Altera o ato das disposições constitucionais transitórias, para instituir o novo regime fiscal, e dá outras providências. 2016. Disponível em: http://www.planalto.gov.br/ccivil_03/constituicao/emendas/emc/ emc95.htm. Acesso em: 20 jan. 2021.

CAMPOS, G. W. de S. O pesadelo macabro da Covid-19 no Brasil: entre negacionismos e desvarios. Trabalho, Educação e Saúde, Rio de Janeiro, v. 18, n. 3, 2020. Disponível em: https://www.scielo.br/pdf/tes/v18n3/01026909-tes-18-3-e00279111.pdf. Acesso em: 12 jan. 2021.

CAMPOS, D. B.; BEZERRA, I. C.; JORGE, M. S. B. Tecnologias do cuidado em saúde mental: práticas e processos da atenção primária. Revista Brasileira de Enfermagem, v. 71, supl. 5, 2018. Disponível em: https://www.scielo.br/ j/reben/a/ppXdx8LHmndvZKXyC3dbKdQ/?lang=pt. Acesso: 28 fev. 2021. CEPRO. Piauí em números. 9. ed. Teresina, 2012. Disponível em: http:// www.cepro.pi.gov.br/download/201306/CEPRO07_8a8208d146.pdf. Acesso em: 3 jan. 2021.

GIOVANELLA, L. et al. A contribuição da atenção primária à saúde na rede SUS de enfrentamento à Covid-19. Saúde em Debate, Rio de Janeiro, v. 44, n. 4, dez. 2020. Disponível em: https://saudeemdebate.org.br/sed/issue/ view/42/v.\%2044\%2C\%20n.\%20ESPECIAL\%204. Acesso: 28 fev. 2021.

IBGE. Censo demográfico. 2010. Disponível em: https://cidades.ibge.gov.br/ ?lang=\&coduf=22\&search=piaui. Acesso em 28 jan. 2021.

IGLESIAS, A.; AVELLAR, L. Z. Matriciamento em saúde mental: práticas e concepções trazidas por equipes de referência, matriciadores e gestores. Ciência e Saúde Coletiva, Rio de Janeiro, v. 24, n. 4. maio 2019. Disponível em: https://www.scielo.br/scielo.php?script=sci_arttext\&pid=S141381232019000401247. Acesso: 28 fev. 2021.

JOAZEIRO, E. M. G.; ARAÚJO, L. J. C.; ROSA, L. C. dos S. Formação e trabaIho coletivo na saúde mental: intersetorialidade e sinergia. Tempus Actas de Saúde Coletiva, Brasília, v. 11, n. 3, 2018. Disponível em: http://www. tem pusactas.unb.br/index.php/tempus/article/view/2482. Acesso em: 16 jan. 2021.

MENDES, A.; CARNUT, L. Capital, Estado, crise e a saúde pública brasileira. SER Social, Brasília, v. 22, n. 46, jan. 2020. Disponível em: https://periodi cos.unb.br/index.php/SER_Social/article/view/25260. Acesso em: 14 maio 2021.

MERHY, E. E. et al. Rede básica, campo de forças e micropolítica: implicações para a gestão e cuidado em saúde. Saúde em Debate, Rio de Janeiro, v. 43, n. especial, 2019. Disponível em: https://www.scielo.br/j/sdeb/a/RXfn Pp73B9Dpcz5pqcVnBdf/?lang=pt\&format=pdf. Acesso em: 14 maio 2021. MINAYO, M. C. S. O desafio do conhecimento: pesquisa qualitativa em saúde. São Paulo: Hucitec, 2006. 


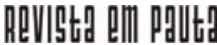

| SAÚDE MENTAL - CARDOSO, F. M. C.; JOAZEIRO, E. M. G. \}

DOI: $10.12957 /$ REP.2022.63474

MINAYO, M. C. de S.; FREIRE, N. P. Pandemia exacerba desigualdades na saúde. Ciência e Saúde Coletiva, Rio de Janeiro, v. 25, n. 9, 2020. Disponível em: https://www.scielo.br/scielo.php?script=sci_arttext\&pid=S141381232020000903555. Acesso em: 18 ago. 2021.

OMS. Relatório mundial de saúde 2008: cuidados de saúde primários. 2008. Disponível em: https://www.who.int/eportuguese/publications/whr08 _pr.pdf?ua=1. Acesso em: 5 maio 2021.

PAIM, J. S. Os sistemas universais de saúde e o futuro do Sistema Único de Saúde (SUS). Saúde em Debate, Rio de Janeiro, v. 43, n. especial, 2019. Disponível em: https://scielosp.org/article/sdeb/2019.v43nspe5/15-28/\#. Acesso em: 31 jan. 2021.

PEREIRA, P. A. P. A intersetorialidade das políticas sociais na perspectiva dialética. In: MONNERAT, G. L.; ALMEIDA, N. L. T.; SOUZA, R. G. A intersetorialidade na agenda das políticas sociais. Campinas: Papel Social, 2014.

PITTA, A. M. F.; COUTINHO, D. M.; ROCHA, C. C. M. Direitos humanos nos Centros de Atenção Psicossocial do Nordeste do Brasil: um estudo avaliativo, tendo como referência o QualityRights - WHO. Saúde em Debate, Rio de Janeiro, v. 39, n. 106, 2015. Disponível em: https://www.scielo.br/pdf/sdeb/ v39n106/0103-1104-sdeb-39-106-00760.pdf. Acesso em: 20 jan. 2021.

SANTOS, M. O dinheiro e o território. In: SANTOS, M. et al. Território e territórios: ensaios sobre o ordenamento territorial. Rio de Janeiro: DP\&A Editora, 2006.

SARACENO, B. Desafíos para la salud mental en tiempos de crisis. Serviço Social e Saúde, Campinas, v. 19, 2020. Disponível em: https://periodicos.sbu.uni camp.br/ojs/index.php/sss/article/view/8665353/26510. Acesso em: 25 maio 2021.

SEIXAS, C. T. et al. A crise como potência: os cuidados de proximidade e a epidemia pela Covid-19. Interface, v. 25, supl. 1, 2021. Disponível em: https:// pesquisa.bvsalud.org/controlecancer/resource/pt/biblio-1134603? src= similardocs. Acesso em: 27 maio 2021.

VASCONCELOS, E. M. Reforma psiquiátrica, tempos sombrios e resistência: diálogos com o marxismo e o Serviço Social. Campinas: Papel Social, 2016.

WERNECK, G. L.; CARVALHO, M. S. A pandemia de Covid-19 no Brasil: crônica de uma crise sanitária anunciada. Cadernos de Saúde Pública, Rio de Janeiro, v. 36, n. 5, 2020. Disponível em: https://www.scielosp.org/ article/csp/2020.v36n5/e00068820/en/. Acesso em: 20 jan. 2021.

DOI: $10.12957 /$ rep.2022.63474

Recebido em 05 de julho de 2021.

Aprovado para publicação em 03 de setembro de 2021.

A Revista Em Pauta: Teoria Social e Realidade Contemporânea está licenciada com uma Licença Creative Commons Atribuição 4.0 Internacional. 